\title{
Neonatal conjunctivitis: aetiology, diagnosis and treatment
}

\author{
Jennifer Perera ${ }^{1}$, Nalini Withana ${ }^{2}$ and H. R. Seneviratne ${ }^{3}$ \\ The Ceylon Journal of Medical Science 1996; 39: 69-73
}

\section{Summary}

In a case control study of 426 unselected deliveries at the De Soysa Hospital for Women, $85(20 \%)$ infants had conjunctivitis. Chlamydia species (spp) and viruses were not detected. Staphylococcus aureus was the commonest pathogen isolated and was detected in $47 \%$ of cases. Klebsiella spp was isolated from $27 \%$. Pseudomonas spp, Streptococcus viridana and coliform isolation rates were not significantly different to that of controls, although significantly higher counts of bacteria were found in the cases. Therefore it would be more useful to the clinician if the laboratory report indicated the severity of infection.

Only $51 \%$ of the isolates were sensitive to the conventionally used antibiotic, chloramphenicol. Treatment with saline washes appear to be sufficient in the first few days of the illness as there is spontaneous resolution of clinical appearance within 48-72 $\mathrm{hr}$ in a majority of patients.

\section{Introduction}

Conjunctivitis is frequently seen in newborn babies. The neonatal conjunctiva is prone to infection not only because there are low levels of antibacterial substances in tears, but also because the tear flow and film are only beginning to develop(1). Staphylococcus aureus, Streptococcus pneumoniae, Haemophilus spp and Neisseria gonorrhoeae are established pathogens. However, Pseudomonas spp. (2), Klebsiella spp, Escherichia coli (3), Streptococcus viridans, Herpes simplex virus type 1 and $\Pi$ (4), adenovirus type 8 (5) and Mycoplasma spp (6) have also been isolated from cases of ophthalmia neonatorum
(ON). Chlamydia trachomatis has also been recognized as an important cause of neonatal conjunctivitis (7). Chlamydial $\mathrm{ON}$ is usually contracted in the intrapartum period but develops after the baby has left the hospital. It does not respond to the commonly used topical antibiotics.

This prospective study was undertaken to establish the incidence, aetiology, natural history and treatment of $\mathrm{ON}$.

\section{Materials and Methods}

A case control study was done. The study population consisted of 426 neonates from consecutive deliveries in the University Unit of the De Soysa Hospital for Women (DSHW) between May to August 1987. The newborns were 1-7 days old during the time of examination. ON was diagnosed by the presence of an overt ocular discharge and/or conjunctival hyperaemia.

The eye discharge was collected from the inferior palpebral conjunctival surface on three cotton wool swabs. One swab was used for making smears on 2 glass slides for Gram and Giemsa staining to examine for pus cells and chlamydial inclusion bodies respectively. The second swab was swirled in sucrose phosphate transport medium and placed in virus transport medium for Chlamydia and virus isolation respectively. The material from the third swab was immediately inoculated at the bed-side on to a blood agar plate followed by plating on MacConkey and chocolate agar plates for isolation of bacteria. The blood and chocolate agar plates were incubated at $37 \mathrm{C}$ in $5 \% \mathrm{CO}_{2}$ for $48 \mathrm{hrs}$, and MacConkey plates at $37 \mathrm{C}$ aerobically.

1 Senior Lecturer, Department of Microbiology, Faculty of Medicine, University of Colombo.

2 Department of Virology, Medical Research Institute, Colombo.

3 Professor, Department of Obstetrics and Gynaecology, Faculty of Medicine, Colombo. 
Colony counts were done using the blood agar plate. To facilitate counting of colonies on blood agar the swab was rolled across the same diameter of the plate twice and streaking was carried out perpendicular to the inoculation line with a bacteriological loop. The bacteria were identified using standard laboratory techniques (8). Antibiotic sensitivity testing was performed using Stokes disk diffusion method (9).

In the Gram stained smear, pus cells in 100 fields were counted to obtain the average numbers of pus cells per field as viewed by the oil immersion objective (HPF; $x$ 1000).

The sample collected on to sucrose phosphate medium was inoculated on to cycloheximide treated McCoy cells for the isolation of Chlamydia trachomatis. After 48 hrs. the cells were stained using Giemsa stain and examined under dark ground microscopy for inclusion bodies.

The samples collected on to the virus transport medium was inoculated on to primary human embryonic kidney cell and Vero cell lines for the isolation of adeno and Herpes simplex viruses respectively and observed for cytopathic effects after 7 days.

A control population of 40 neonates without conjunctivitis who were matched for age at the onset of symptoms and type of delivery were similarly examined.

Treatment was carried out in the usual manner, ie. sterile saline washes in mild cases and chloramphenicol eye drops 6 hourly in severe cases, as judged by the clinical signs. One month after discharge from hospital a questionnaire was sent to all mothers of babies with $\mathrm{ON}$ to determine the type and response to treatment.

\section{Results}

During the period of study there were 426 deliveries and 85 babies had conjunctivitis resulting in a $20 \%$ incidence. Table 1 shows the groups of organisms isolated in both groups(cases and controls). Viruses and Chlamydia spp were not detected. Thus the aetiology was exclusively bacterial. $35 \%(14 / 40)$ of the control group did not show any bacterial growth in contrast to $2.3 \%(2 / 85)$ in the group with conjunctivitis.

Table 1. Incidence of groups of organisms isolated from cases and controls

$\begin{array}{lll}\begin{array}{l}\text { Group of organisms Cases (\%) } \\ \text { n }\end{array} & \begin{array}{c}\text { Controls (\%) } \\ \mathrm{n}=40\end{array} \\ \begin{array}{l}\text { Pathogenic bacteria } \\ \begin{array}{l}\text { Nonpathogenic } \\ \text { bacteria }\end{array}\end{array} & 77(90.5) & 18(45)^{*} \\ \begin{array}{l}\text { Adeno/Herpes Simplex } \\ \text { virus }\end{array} & 6(7.0) & 8(20) \\ \begin{array}{l}\text { Chlamydin } \\ \text { No microorganisms }\end{array} & 0 & 0 \\ & 2(2.3) & 14(35)^{*} \\ \end{array}$

$$
* \mathrm{P}<0.001, \mathrm{Chi}^{2}
$$

Table 2 lists the main species of bacteria isolated from the study group. From each patient only the predominant bacterial species isolated were considered in the analysis of results. Staphylococcus epidermidis and diphtheroids which are skin commensals were found in both test and control groups. The bacteria conventionally accepted as pathogens were found more often among cases than among controls. However among these only Staph aureus and Klebsiella spp were isolated in a significantly higher number of cases than from controls. Two babies with symptoms had mixed infections with Staph aureus and Klebsiella species. $S$ viridans, Pseudomonas spp and coliforms which are often accepted as aetiological agents of neonatal conjunctivitis were not significantly different in the two groups. However, the colony counts of these bacteria were found to be significantly higher in the test group than among the controls (Table 3). Although Branhamella catarrhalis has been reported from neonates with conjunctivitis in other studies (10), it was not isolated in our series. 
Table 2. Incidence of the predominant bacterial species isolated from the study group

\begin{tabular}{|lll|}
\hline $\begin{array}{l}\text { Bacteria } \\
\text { isolated }\end{array}$ & $\begin{array}{c}\text { Cases (\%) } \\
\mathrm{n}=85\end{array}$ & $\begin{array}{c}\text { Controls (\%) } \\
\mathrm{n}=40\end{array}$ \\
\hline S. aureus & $40(47)$ & $10(32.5)^{*}$ \\
Klebsiella spp & $23(27)$ & $2(5)+$ \\
S. viridans & $5(5.8)$ & $2(5)$ \\
Pseuddomonns spp & $4(4.7)$ & $1(2.5)$ \\
Coliforms & $3(3.5)$ & - \\
S. epidermidis & $4(4.7)$ & $7(17.5)$ \\
Diphtheroids & $2(2.3)$ & $1(2.5)$ \\
\hline
\end{tabular}

${ }^{*} \mathrm{p}<0.5, \mathrm{Chi}^{2} \quad+\mathrm{p}<0.01, \mathrm{Chi}^{2}$

$80 \%$ of babies with ON showed pus cells on Gram stained smears compared to $20 \%$ in the control group. The number of pus cells/high
Table 3. Average number of colonies of pathogenic bacteria isolated from cases and controls

\begin{tabular}{|lcc|}
\hline & $\begin{array}{c}\text { Cases (\%) } \\
\mathrm{n}=75\end{array}$ & $\begin{array}{c}\text { Controls (\%) } \\
\mathrm{n}=15\end{array}$ \\
\hline S. nureus & 56.2 & 5.1 \\
Klebsiella spp & 39.5 & 2.5 \\
S. viridans & 56.4 & 6.0 \\
Pseudomonas spp & 49.2 & 2.0 \\
Chlamydia & 0 & 0 \\
& & \\
\hline
\end{tabular}

$* \mathrm{P}<0.001, \mathrm{Chi}^{2}$

power field (1000X) correlated well with the numbers of organisms found in each patient (Figure 1).

Fig. 1 Average number of pus cells in Gram stain vs number of colonies in the study group

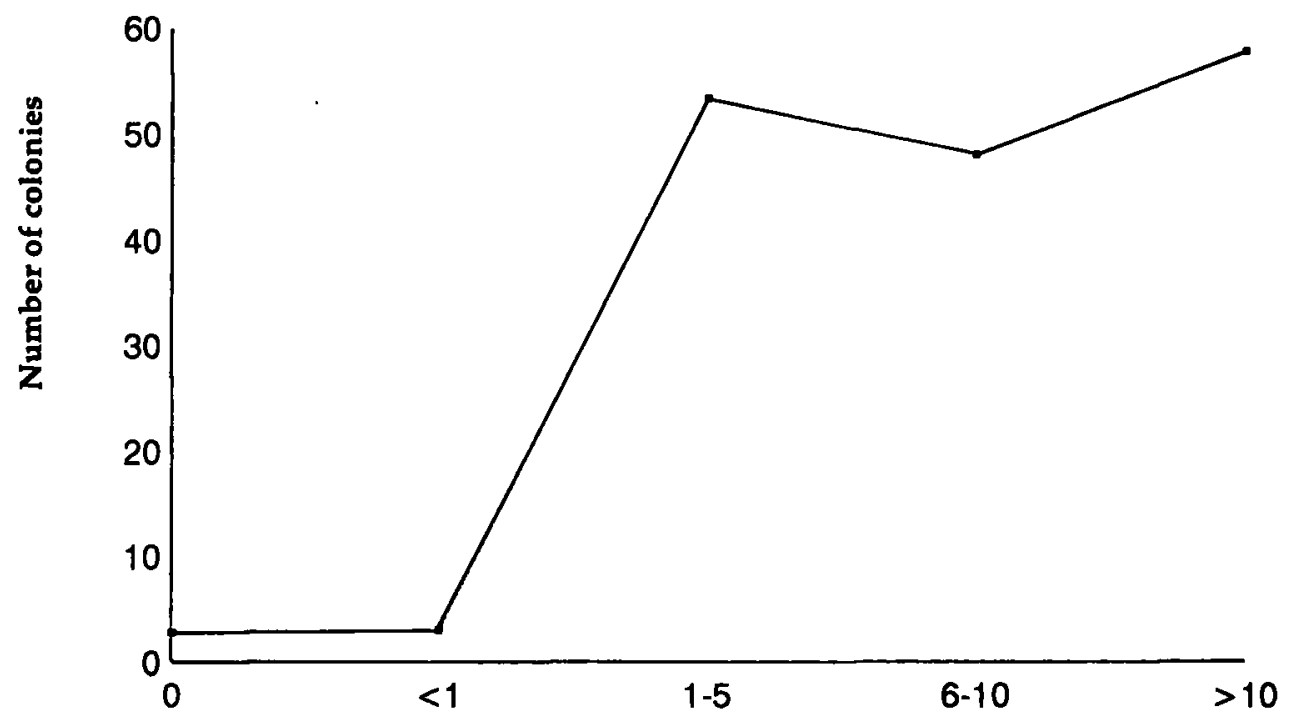

Average number of pus cells/HPF (x1000) 
41 out of the 85 parents of the babies who had $\mathrm{ON}$ responded to the questionnaire. Out of the $41,27(66.8 \%)$ had received chloramphenicol eye drops. The remaining patients had received sterile saline washes. 4 out of the $41(9.7 \%)$ continued to have the eye discharge on and off even after one month of local antibiotic treatment, but others were rid of symptoms by two weeks irrespective of whether they received antibiotics or saline washes.

$49 \%$ of isolates showed chloramphenicol resistance on the antibiotic sensitivity test. Out of the 37 babies, who recovered completely 18 had chloramphenicol resistant strains and 11 out of the 18 had used chloramphenicol eye drops for an average period of 5 days (range being two days to two weeks). The remaining 7 babies with chloramphenicol resistant strains had no antibiotics yet both groups recovered irrespective of treatment.

Among the 19 babies who harboured chloramphenicol sensitive strains only 9 had received chloramphenicol eye drops. The 4 babies who continued to have an eye discharge for over one month in spite of antibiotic treatment were not available for follow up by microbiological examination. Among these 4 babies 2 had bacterial strains sensitive to chloramphenicol and one had a chloramphenicol resistant strain. The fourth patient only had significant numbers of colonies of $S$ epidermidis on microbiological examination.

\section{Discussion}

From 426 unselected deliveries at the University unit of the DSHW for women, $20 \%$ of infants developed conjunctivitis. Staph aureus was the commonest (47\%) pathogen isolated probably due to cross-infection within the unit. Staph aureus could also be transmitted from a carrier mother to the newborn and the carrier status of the mother was not determined in this study. In a study carried out in Southampton, U.K. in 1982 a $12 \%$ incidence of ON has been found (11). In the Southampton study Staph aureus was not found more often among cases than among controls and attributed it to lack of cross- infection within the unit. Yet other workers have found it to be an important pathogen in ON $(12,13)$. A study carried out in the De Soysa Eye Institute, Kandy in 1940's found Staphylococcus $26 \%$, Gonococcus 24\%, $H$ ducreyi $10 \%$, Pneumococcus $2 \%$, Morax-Axenfeld $10 \%$ and undetermined $34 \%$, in patients presenting with conjunctivitis and is the only study previously published from Sri Lanka (14). The results can not be compared with the present study as the study populations are different.

Klebsiella spp was isolated from $27 \%$ of neonates with symptoms. This was not found to be a significant pathogen in other studies. The average numbers of Pseudomonas spp, $S$ viridans and coliforms per specimen were significantly higher in the group with symptoms although the isolation rate of these organisms were not significantly different to those of the control group. Therefore it is more useful to report as mild, moderate or heavy growth to indicate the severity of infection. The more accurate methods of determining the number of bacteria in specimens were not used in the study due to technical difficulties. Ideally a fixed aliquot of conjunctival fluid or standard loop method should have been used for determining colony counts.

Adenovirus conjunctivitis in neonates is reported to occur in outbreaks. In our series we did not isolate adenovirus or herpes virus from any of the patients. $C$ trachomatis was not detected in any of the babies. The incubation period for chlamydial eye infection is estimated to be between 3-19 days on the assumption that the infants are infected intrapartum. One of the reasons for not detecting $C$ trachomatis may be because that majority $(75 \%)$ of the babies in the study group were less than three days old at the time of specimen collection. These organisms should be sought for in cases of ON resistant to treatment as Chlamydia species are sensitive only to tetracycline and erythromycin among the commonly used antibiotics.

The initial inadequate tear flow rather than an infective aetiology is a likely explanation of our failure to isolate pathogenic organisms from $2.3 \%$ of cases. This hypothesis is supported by 
the following observations. Firstly the natural history of ON is for a tendency towards spontaneous resolution within 48-72 hrs, without any specific treatment. In out study among babies who received topical chloramphenicol treatment only $51 \%$ of the isolates were sensitive to chloramphenicol. Yet both groups recovered completely, irrespective of whether they had either chloramphenicol sensitive strains or not. In babies from whom chloramphenicol sensitive strains were isolated recovery rates were similar, irrespective of whether they received sterile saline washes or chloramphenicol eye drops. Therefore it is suggested that treatment with sterile saline washes may suffice for the first $72 \mathrm{hrs}$. However, if no response is observed at $72 \mathrm{hrs}$. topical chloramphenicol should be used. If the conjunctivitis persists after two weeks the patient should be investigated for chlamydial infection or an anatomical abnormality.

\section{Acknowledgments}

We thank the house officers of the University Unit for the assistance in identification of patients, Ms C. Ranjithan and Mr. S. Gamage for technical assistance and University of Colombo for financial assistance.

\section{References}

1. Etches PC, Leahy F, Harris D, Baird JD. Lysozyme in the tears of newborn babies. Archives of Diseases of Childhood 1979; 54: 218-21.

2. Cole GF, Davies DP, Austin DJ. Pseudomonas ophthalmia neonatorum: cause of blindness. British Medical Journal 1980; ii: 440-441.

3. McGill RET. Neonatal eye infections. Communicable diseases (Scotland) weekly report. 1979; 22: ix.

4. Csonka .GW, Confalik Ed. Chlamydial, gonococcal and herpes virus infection in . neonates. Postgraduate Graduate Medical Journal. 1977; 53: 592-594.
5. Dawson CR, Jawetz E, Hanna L, Winn W, Thompson JG. A family out-break of adenovirus 8 infection. American Journal of Hygiene 1960; 72: 279-285.

6. Jones DM, Tolin B. Neonatal eye infections due to $M$ hominis. British Medical Journal 1968; iii: 467-468.

7. Chandler JW, Alexander FR, Pfeiffer JA, Wang SP, Holmes KK, English $M$. Ophthalmia neonatorum associated with maternal chlamydial infection. Transactions of the Academy of Ophthalmology and Otolaryngology 1977; 83: 302-308.

8. Cowan ST, Steel KJ. Manual for the identification of Medical Bacteria. Editors G I Barrow, RK Fathom; 3rd Edition. Cambridge University Press 1991.

9. Stokes EJ, Ridgheway GL. Clinical Bacteriology. London: Edward Arnold Publishers 1980.

10. Spark RP, Dahlberg PW, LaBelle JW. Pseudogonococcal ophthalmia neonatorum. Branhamella catarrhalis conjunctivitis. American Journal of Clinical Pathology 1979; 72: 471-473.

11. Pierce JM, Ward ME, Seal DV. Ophthalmia neonatorum in the 1980s: incidence, aetiology and treatment. British Journal of Ophthalmology 1982; 66: 728-731.

12. Armstrong JHY, Zacarius F, Rein MF. Ophthalmia neonatorum. A chart review. Paediatrics 1976; 57: 884-892.

13. Vonen M. Prophylaxis of ophthalmia neonatorum. Acta Ophthalmol (kbh) 1965; suppl 79: 1-70.

14. Sivasubramanium P. Ophthalmia neonatorum. Journal of Jaffna Clinical Society 1955; 2: 88-93. 